STRUCTURAL SCIENCE CRYSTAL ENGINEERING MATERIALS

ISSN 2052-5206
Keywords: book review; cementitious materials.

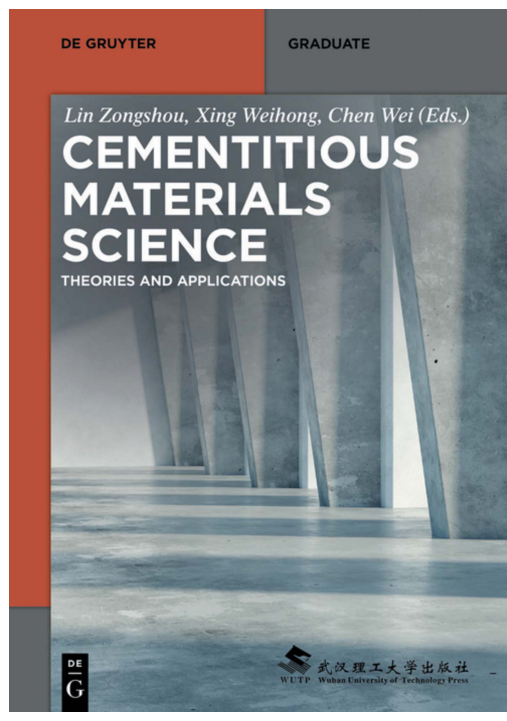

(C) 2021 International Union of Crystallography

\section{Cementitious Materials Science. Theories and Applications. Edited by Lin Zongshou, Xing Weihong and Chen Wei. De Gruyter, 2019. XIII + pp. 403, Paperback. Price EUR 68.95. ISBN 978-3- 11-057209-4}

\author{
John Provis*
}

Department of Materials Science and Engineering, The University of Sheffield, Sir Robert Hadfield Building, Mappin St, Sheffield, S1 3JD, United Kingdom. *Correspondence e-mail: j.provis@sheffield.ac.uk

This book is an English language translation of an important Chinese graduate-level teaching text on the materials science of cements. Its scope is quite broad within this topic, covering historical binding materials, conventional (Portland) cement and its variants and blends, lime, gypsum, and a variety of special cements. It is a 2019 translation of the 2014 (third) Chinese edition of this text, which appears to be focused at a graduate level. However, the key technical content appears to have been derived from earlier editions of the Chinese text, dating back to an original 1980 edition. This is particularly evident in the complete absence of any mention in this new edition of sustainable development, $\mathrm{CO}_{2}$ emissions or waste utilization. Given that these three points are currently the core focus of almost all research and development in the international cement sector, it seems inconceivable that they are omitted from a text intended to train graduate student engineers in the design and use of cementitious materials; this is a very significant shortcoming in the book.

The book is overall mostly well presented. The graphics and tables are largely effective in design and execution, although the few SEM micrographs that are used to illustrate the discussion of cement microstructures appear to be rather old and are not of high resolution. There are some minor but frustrating typographical errors in places, including the repeated use of 'A1' in place of 'Al' as the chemical symbol for aluminium. The English language translation is uneven in parts, but is nonetheless readable and comprehensible. The index is somewhat helpful but far from exhaustive, and somewhat erratic in its degree of coverage of different topics and keywords.

A significant omission is any form of reference to the primary technical literature throughout the text; the short bibliography presented at the end of the book lists 16 Chinese language textbooks/handbooks, but there are no in-text citations, footnotes or end-of-chapter reading lists as are found in many other graduate-level texts. Some key pieces of information are attributed to particular authors, but listing only the author surname and no further details. This has the unfortunate effect that it is rather difficult to judge the currency of some of the information presented, or to identify sources on specific topics for further reading and study.

The book is presented in seven chapters: (1) Introduction; (2) Common Portland Cement; (3) Characteristic Cement and Special Cement; (4) Gypsum; (5) Lime; (6) Magnesia Cementitious Material; (7) Other Binders. Each chapter has a short set of review questions for students as its closing section. The distribution of material between the chapters is logical, in that Chapter 2 on Portland cement occupies approximately half of the total length of the book, corresponding to the essential role of this type of cement in the global industry. Chapter 2 covers Portland cement production, cement powder characteristics, engineering properties in the fresh and hardened states, and supplementary cementitious materials/blended cements.

In terms of technical content, the coverage of Portland cement production and basic properties is largely well done. However, topics related to supplementary cementitious materials and blended cements are given only a very small amount of attention relative to their importance in the market (now dominating worldwide cementitious materials 
usage); these are covered in a very cursory manner in a fourpage sub-section within the Portland cement chapter. The discussion of Portland cement hydration mechanisms gives an interesting historical perspective from the 1880 s onwards, but does not include the advances in understanding that have taken place in the past 20-30 years; this section appears to have been retained from earlier editions of the Chinese language text and needs updating. Similar comments apply to the discussion of cement clinker and hydrate phases and their nano-/micro-structures; modern crystallographic and spectroscopic techniques are not mentioned, and the literature on which the discussion is based only extends to the late 1970s. This cutoff date is very unfortunate, as very soon after this, solid-state nuclear magnetic resonance spectroscopy began to be used to obtain much more detailed understanding of the silicate chain structures in the calcium silicate hydrates which dominate hydrated Portland cement phase assemblages, and advanced diffractometry has since that time also yielded very much higher-resolution structure solutions for the key (and complex) silicate and aluminate phases in both anhydrous and hydrated cements. This information is lacking from the text and leaves the crystallographic description of essential phases rather incomplete. Other key cement analytical techniques, for example, isothermal calorimetry and most forms of spectroscopy, are also largely neglected in the discussion.

Probably the most interesting and valuable part of the book, at least to an international audience, is the section of Chapter 2 which discusses Chinese cement testing and material standards, and the requirements imposed by these regulatory documents. Chinese standards are often cited in technical publications published by authors from that nation, but it is generally difficult to obtain English language translations of the key stipulations of those standards. The fact that this book does contain such information is a valuable thing to researchers in the field, who may find this to be a helpful reference point. Referring to the primary intention of the book as a graduate-level text this is probably less relevant to a student reader, but the opportunity for practitioners to compare Chinese standards to other international documents is of some interest.

Most of the remainder of the book is then dedicated to materials other than Portland cement, although variant Portland cements with special characteristics (e.g. rapid hardening, sulfate resistant, lower-heat, expansive, and others) are also discussed along with their non-Portland counterparts. There is significant value in the coverage of clinkerization processes and technical characteristics of a range of specialty clinkers here, including references to a variety of Chinese standards for these materials, but once more hamstrung by the absence of references to primary technical literature that would enable the interested reader to investigate beyond the necessarily brief summaries of each material given here. There is not a clear division between the 'special cements' covered in Chapter 3 and the 'other binders' covered in Chapter 7; waterglass appears as subsections in both chapters, and it is not clear what is the distinction between 'binder' and 'cement' in this classification, as several of the binders in Chapter 7 are named within the text as being cements. It appears that Chapter 7 may have been added in later additions of the original text, as the information provided here is generally more updated than the remainder of the book. However, parts of this chapter are problematically confusing to the reader, particularly the part related to 'geopolymer' cements, which conflates a variety of different materials (high- and lowcalcium) into a single discussion that does not really give enough information to be comprehensible to student readers.

Chapters 4 and 5 on gypsum and lime are relatively complete, although with some erratic English usage that distracts in places from the meaning of the text. The lime chapter in particular is much stronger in engineering aspects than in description of the underlying science, but also gives an interesting perspective on the requirements imposed by Chinese national standards for this material. Chapter 6 on magnesia cements covers broader technical production and usage of these materials without providing much depth in terms of materials science.

Overall, this is a book with some significant shortcomings, but which also gives a somewhat unique perspective (from an international viewpoint) into cementitious materials as they are taught, produced and used in China. As China produces and uses more than half of all global cement, this is an important point in and of itself. For these reasons, it is more likely to find a home on the shelves of researchers seeking to understand Chinese cement research and production, rather than on the shelves of graduate students seeking to understand cement materials science. It is in many ways an interesting but deeply flawed text, providing information that is not readily available elsewhere, but uneven in coverage and technical currency, and (most critically) lacking consideration of sustainability as the key driver of cement developments in the modern era. 